\title{
Determining power-energy parameters of combined rolling-extrusion process for low-plastic aluminium alloys
}

\author{
S. B. Sidelnikov, Professor, Head of the Chair of Metals Pressure Treatment, School of Non-Ferrous Metals \\ and Material Science ${ }^{1}$ \\ R. I. Galiev, Assistant Professor, Chair of Metals Pressure Treatment, School of Non-Ferrous Metals and \\ Material Science ${ }^{1}$, e-mail: gri1979@mail.ru \\ V. M. Bespalov, Assistant Professor, Chair of Metals Pressure Treatment, School of Non-Ferrous Metals \\ and Material Science ${ }^{1}$ \\ A. P. Samchuk, Post-Graduate Student, Chair of Metals Pressure Treatment, School of Non-Ferrous Metals \\ and Material Science ${ }^{1}$ \\ ${ }^{1}$ Siberian Federal University, Krasnoyarsk, Russia.
}

\begin{abstract}
Presented are the results of theoretical study of energy-power parameters of combined rolling-andpressing (CRP) process of press-products of AMg6 (АMr6), 01417, 8176 alloys.

Choice of these alloys is governed by the fact that their alloyage by different elements like titanium, iron, lanthanum, cerium etc., causes difficulties on non-cutting shaping and producing long-length semifinished products of electrotechnical destination. It is shown that making such semifinished goods of these alloys is non-manufacturable even with the use of traditional direct pressing operations on horizontal hydraulic presses; it is characterized by increased labour-intensiveness and requires higher power inputs. In this connection, the goal to be sought in this paper is to investigate possibility of processing the above mentioned alloys by method of combined continuous rolling-extrusion (CRE) as well as to determine powerenergy parameters of the process depending on varying temperature of semifinished product, degree and rate of metal deformation.

The efforts, affecting the die and the rolls during combined processing has been calculated with the use of rheological characteristics of selected alloys, determined by the hot torsion method; analysis of their changes, depending on deformative and temperature-speed parameters for various combinations of the groove and diameters of the die has been also carried out. Ascertained have been the changing mechanism of energy-power parameters and their limiting value on realizing the process of combined rolling-extrusion at the combined processing plants of different design in the given range of varying parameters. There also has been made the recommendations on designing the technology of low-plastic alloys combined treatment for a CCRE-4 (СЛиПП-4) experimental-industrial plant placed into operation at Irkutsk aluminium smelter.
\end{abstract}

Key words: aluminium alloys, modification, titanium, boron, combined processes, casting, rolling, pressing, rheological characteristics, mechanical characteristics.

DOI: $10.17580 / \mathrm{nfm} .2018 .01 .06$

\section{Introduction}

A luminium alloys selected for investigations are used in manufacturing electrode wire and electricalpurpose wire; this explains their wide use in electrical industry. Wire of 01417 alloys is used for manufacturing airborne wires in modern aircrafts; wire of 8176 alloy is used for producing current-carrying core of mounting wires [1]. The function of the wire of AMg6 alloy is somewhat different: it is mainly used as an electrode one in when producing different constructions [2]. In the manufacture of semifinished products for further wiredrawing with the wire diameter less than $2 \mathrm{~mm}$, it is essential to obtain the bars having margin of safety and plasticity.
However, some features of doping of the selected alloys by various elements like titanium, iron, lanthanum, cerium etc., cause difficulties during their treatment, even with the use of traditional direct pressing operations on highpowered horizontal hydraulic presses. In other words, they are characterized by non-manufacturability being used in manufacturing long-length semifinished products. Besides, power inputs in the press-goods production by this method are rather high [3], which leads to significant prime cost growth of the pressed goods made of aluminium alloys. In contrast to extrusion, applying casting and rolling technologies on casting and rolling units (CRU) are characterized by continuity of processing cycle, and so they are more productive and guarantee higher yield as compared with it. At the same time, these technologies are 
Table 1

Comparative performance indicators of technologies for production of long-length products of aluminium alloys

\begin{tabular}{|c|c|c|c|}
\hline \multirow{2}{*}{ Indicator } & \multicolumn{3}{|c|}{ Technology } \\
\hline & Extrusion & CCR & CCRE \\
\hline Continuity & $\begin{array}{l}\text { Provides only semicontinuous extru- } \\
\text { sion with butt welding of shapes }\end{array}$ & Provides & Provides \\
\hline Set of equipment & $\begin{array}{l}\text { Line with horizontal hydraulic press, } \\
16-20 \mathrm{MN}\end{array}$ & $15-20$ and more mill stands & One mill stand \\
\hline Length of equipment, m & Up to 80 & $50-70$ & $10-15$ \\
\hline Energy intensity & $\begin{array}{l}\text { Individual drive for hydraulic press } \\
\text { and pump-and-accumulator station }\end{array}$ & $\begin{array}{l}\text { Group drive for } 15-20 \text { mill } \\
\text { stands and casting machine }\end{array}$ & Individual drive for 1 mill stand \\
\hline $\begin{array}{l}\text { Flexibility of switching from } \\
\text { one shape type to another }\end{array}$ & $\begin{array}{l}\text { Is provided by quick change of extru- } \\
\text { sion tool }\end{array}$ & $\begin{array}{l}\text { Available is only wire rod of } \\
\text { circular cross-section with } \\
\text { diameter of } 9-15 \mathrm{~mm}\end{array}$ & $\begin{array}{l}\text { Is provided by quick change of } \\
\text { extrusion tool }\end{array}$ \\
\hline Yield, \% & $75-77$ & $80-90$ & $90-95$ \\
\hline $\begin{array}{l}\text { Practicability of the aluminium } \\
\text { alloys processing }\end{array}$ & All wrought alloys & An ABE only & All wrought alloys \\
\hline Productivity, ton per hour & Up to 1 & From 2.5 to 8 & From 2.5 to 8 \\
\hline
\end{tabular}

basically used in industrial production for rod manufacturing predominantly of A5E and A7E grade aluminium and of ABE alloy to a lesser degree [1].

Analysis of the findings of investigations concerning low-plastic alloys behaviour on casting, deformation and thermal treatment [4-17], allows to conclude that the overall non-uniform pressing scheme should be applied for their effective treatment. The scheme such as that is realized during extrusion; the metal at this has maximum plasticity and is not subject to defects (cracks) formation, typical for rolling, for example. However rolling is perhaps the only practically used method of metals pressure treatment, which allows to organize continuous cycle of metal processing and to achieve maximum performance.

Currently combined and joint treatments methods are in increasing frequency used in the long-length deformed semifinished products manufacturing of aluminium alloys [18]. Use of graded rolling operations allows to provide treatment continuity and availability of active friction forces required for the complete product pressing-out. Extrusion allows to obtain the die-preassigned configurations and size of the products at high degrees of deformation, which make possible their manufacturing in a single rolling mill in one processing cycle. Combination of these operations with continuous casting on CCRE plants permits to essentially lessen number of technological conversion stages and to decrease labourintensiveness and power intensity of engineering procedure.

Table 1 contains the comparative performance indicators of extrusion technology and continuous casting-rolling technology (CCR) on casting and rolling units (CRU) and technology of combined casting and rolling-extrusion (CCRE) in the version of ingotless metal treatment. It can be seen that the traditionally applied technologies are second to the CCRE one.
Nevertheless the main disadvantage of new energysaving technologies of combined processing is slow pace of their manufacturing application. To date only one such plant, namely CCRE-4 with rod of aluminium alloys output up to 4 ton per hour, has been set in operation at Irkutsk aluminium smelter. One of the factors, binding application of such technologies and equipment, is absence of data for their design, choosing the power of drive motor of combined processing plants as well as die-to-rolls clamping force.

It is especially topical for low-plastic and non-manufacturable alloys, which are difficult-to-deform using the above-mentioned traditional treatment methods.

In this connection, solved in the paper has been the problem on determining the energy-power parameters of AMg6, 01417, 8176 alloys combined processing with the blank temperature as well as metal deformation degree and rate variation in order to select an equipment for manufacturing long-length deformed semifinished products.

\section{Research procedure}

In order to analyse the process under investigation, data on dimensionless and geometrical parameters of different combined processing plants has been used (Table 2). Dimensionless parameters have been applied for a single-valued description of the deformation focus form and size; they further have been used for characterizing shape of the groove, die, semifinished product and press-goods.

Chemical composition of the alloys under investigation is presented Table 3 (aluminium is a base).

\section{Results of investigation and their analysis}

Correct calculation of CRE energy-power parameters requires knowledge of rheological properties of the alloys under study. Thus first stage of investigation has 
involved the experimental study for their evaluation at a hot torsion unit under different temperature and speed parameters [19].

The study has resulted in obtaining data on resistance to deformation $\sigma_{s}$ for alloys under consideration (Fig. 1) in relatively wide range of strain rates $(\xi)$ and deformation degrees ( $\ln \mu$, where $\mu$ - reduction ratio during extrusion) at two temperature values of processing semifinished products $T_{s}\left(400{ }^{\circ} \mathrm{C}\right.$ and $\left.550{ }^{\circ} \mathrm{C}\right)$.

Strain rate for parameters of combined treatment processes (see Table 2) was calculated with the following formula [20]:

$$
\xi=\frac{\pi n \sqrt{0,5 D_{0}\left(h_{0}-h\right)}}{30 h_{0}} .
$$

On the second research stage, the energy-power characteristics of combined rolling-extrusion process with preset geometrical and dimensionless parameters (see Table 2) and given values of rheological properties of the alloys under investigation. Flowchart of combined rollingextrusion is represented in Fig. 2; it includes the following steps: metal of a billet is gripped out in the closed grooves of the rolls; it undergoes intensive plastic deformation in the area immediately before the die that covers the groove at the

Table 2

Data for calculating the combined rolling-extrusion process

\begin{tabular}{|c|c|c|c|c|}
\hline \multirow{2}{*}{ Value } & \multicolumn{3}{|c|}{ Plant type } & \multirow{2}{*}{$\begin{array}{c}\text { Dimensionless } \\
\text { parameter }\end{array}$} \\
\hline & CRE-200 & CCRE-2.5 & CCRE-4 & \\
\hline Diameter of roll with a protrusion $D_{1}, \mathrm{~mm}$ & 214 & 462 & 428 & - \\
\hline Diameter of roll with a groove $D_{2}, \mathrm{~mm}$ & 164 & 394 & 428 & - \\
\hline Minimum gauge height $h, \mathrm{~mm}$ & 7 & 10 & 19 & - \\
\hline Speed of rolls rotation, rpm & $5-14$ & $0-15$ & $0-30$ & - \\
\hline Average diameter of rolls $D_{0}, \mathrm{~mm}$ & 189 & 428 & 428 & $A=\left(D_{0}-h\right) / h$ \\
\hline Groove width $b, \mathrm{~mm}$ & 15 & 22 & 42 & $\tilde{b}=b / h$ \\
\hline Initial height of semiproduct $h_{0}, \mathrm{~mm}$ & 14 & 20 & 42 & $h_{0}=h_{0} / h$ \\
\hline Initial width of semiproduct $b_{0}, \mathrm{~mm}$ & 14 & 20 & 40 & $\tilde{b}_{0}=b_{0} / h$ \\
\hline Height of die face $h_{\mathrm{df}}, \mathrm{mm}$ & 20 & 25 & 31 & $\tilde{h}_{\mathrm{df}}=h_{\mathrm{df}} / h$ \\
\hline Diameter of press-product $d, \mathrm{~mm}$ & $7-9$ & $9-12$ & $9-15$ & $h_{1}=d / h$ \\
\hline
\end{tabular}

outlet from the rolls and owing to active friction forces is squirted through the die aperture with a given shape and size of the press-product. In this case, the process itself is realized in a continuous mode, and the resulting semifinished product is reeled on the receiving device (coiler).

It is agreed that rolls with a groove and a protrusion, forming a rectangular box-type groove, rotate towards each other at a speed of $\omega$. At the third plant (CCRE-4), the effective roll diameters are taken equal, so in that case the press-product extrusion molding will be carried out only by means of active friction forces, brought by the metal contacting roll surfaces with the length of $L_{1}+L_{2}$, which is the total length of the gripping zone during rolling $\left(L_{1}\right)$ and the pressing-out zone $\left(L_{2}\right)$.

The variational problem solving by the full power minimum method [18] has allowed to obtain a numerical data file on magnitude of the forces affecting the die $P_{\mathrm{die}}$ and rolls $P_{\text {roll }}$ as well as their dependence on dimensionless parameters of the rolling-extrusion process, using which the energy-power parameters have been determined for treatment the aluminium alloys under investigation at CRE-200 and CCRE-2.5 laboratory plants and on CCRE-4 experimental-industrial plant of Irkutsk aluminium smelter (see Table 2).

Calculations have been implemented for two temperature levels $\left(T_{s}=400{ }^{\circ} \mathrm{C}\right.$ and $\left.T_{s}=550{ }^{\circ} \mathrm{C}\right)$, various values of deformation rate, and also for three reduction ratio values $(4.4,7.3,14.3)$, characterising deformation degree on the pressproduct extrusion.

Values of the energy-power parameters for a CRE-200 plant are enumerated in Table 4. It can be noticed that for a groove with dimensions in the minimal section of $7 \times 15 \mathrm{~mm}$, the force on the rolls is not higher than $360 \mathrm{kN}$, and the force on the die $-350 \mathrm{kN}$ even at a temperature of $400{ }^{\circ} \mathrm{C}$. Moreover, strain values grow as reduction ratio increases. Increasing the temperature up to $550{ }^{\circ} \mathrm{C}$ makes the strain lowering almost by a factor of 2 or 3. Rise of deformation rate

Table 3

Chemical composition of aluminium alloys, \%

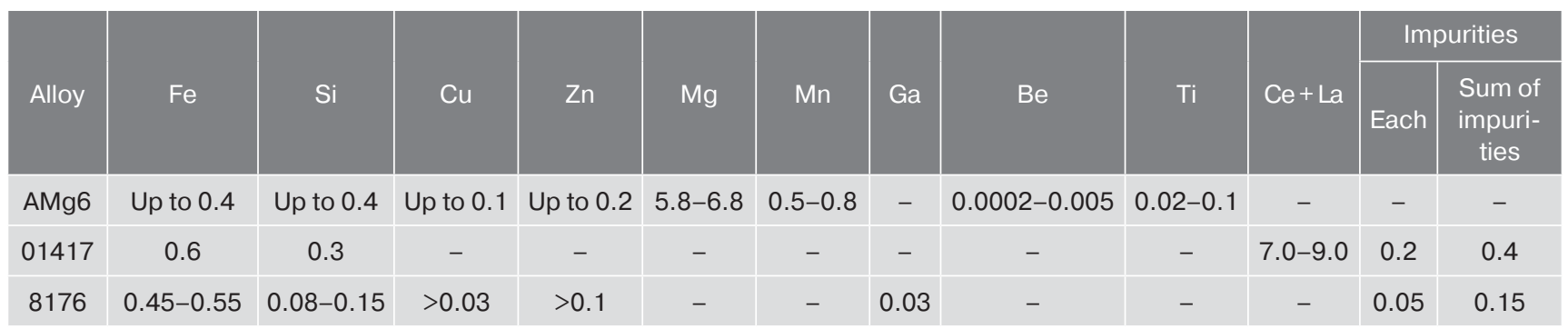



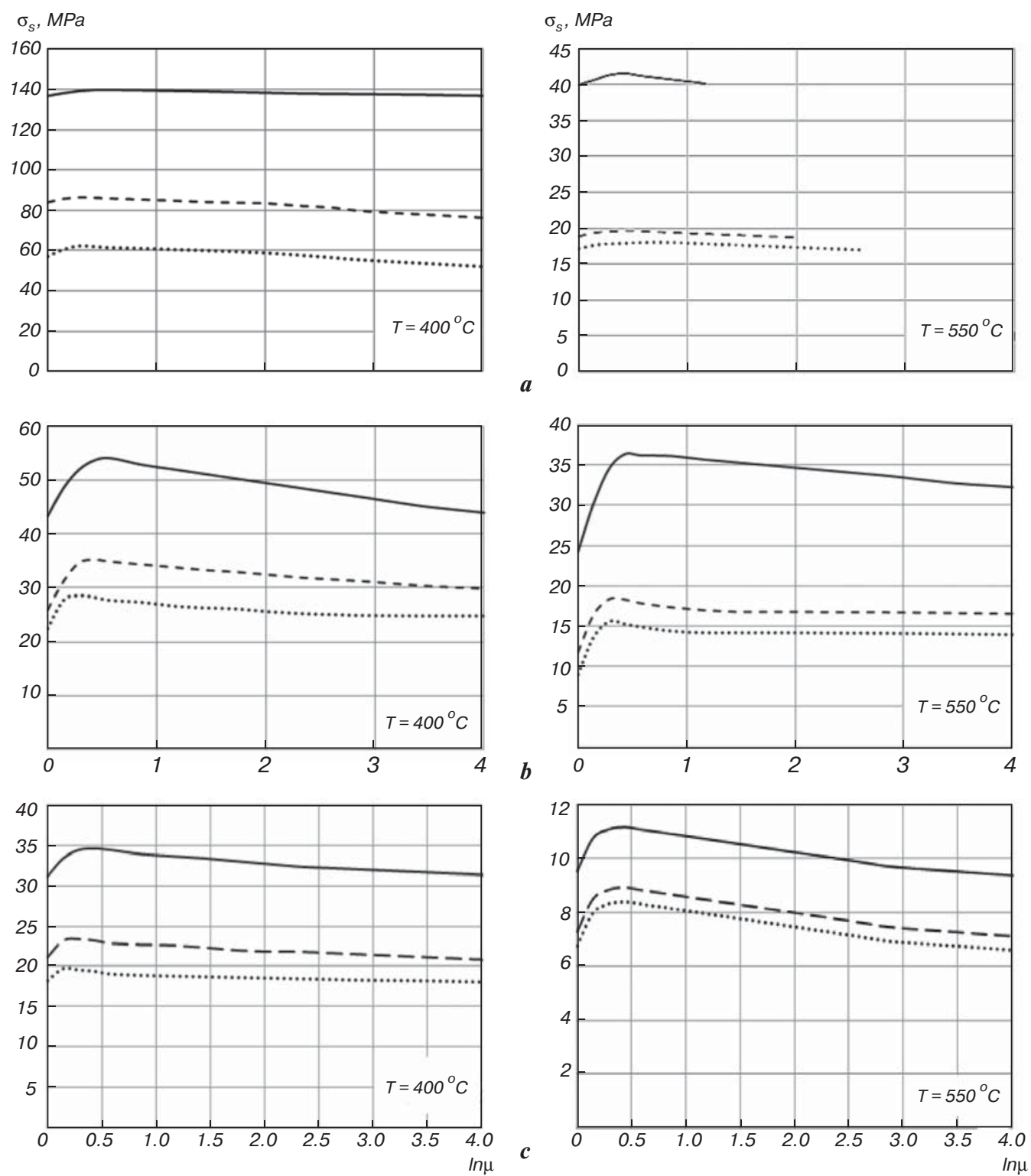

Fig. 1. Dependence of resistance to deformation $\sigma_{s}$ of alloy upon logarithmic deformation degree $\ln \mu$ at various deformation rates $\xi$ : $a-\mathrm{AMg} 6$ alloy; $b-01417$ alloy; $c-8176$ alloy;

…...... $\xi=0.5 \mathrm{~s}^{-1} ;------\xi=1.5 \mathrm{~s}^{-1} ; \square \xi=10.0 \mathrm{~s}^{-1}$

leads to high-speed metal hardening and growth of the energy-power parameters of CRE process.

Maximum values of the energy-power parameters have been obtained for AMg6 alloy, wцhich has the highest resistance to deformation. It should be noted that calculation at high rates and degrees of deformation has not been performed for AMg6 alloy because no data on rheological properties has been obtained under such temperature and speed conditions of the process due to samples destruction (see Fig. 1).

Trend of the energy-power parameters during combined rolling-extrusion process on increase in the groove size for 01417 and 8176 alloys on CCRE-2.5 and CCRE-4 plants (Fig. 3, 4) remains the same as that in case of processing on CRE-200 plant and is confirmed by the results of experimental study [18, 21-22].

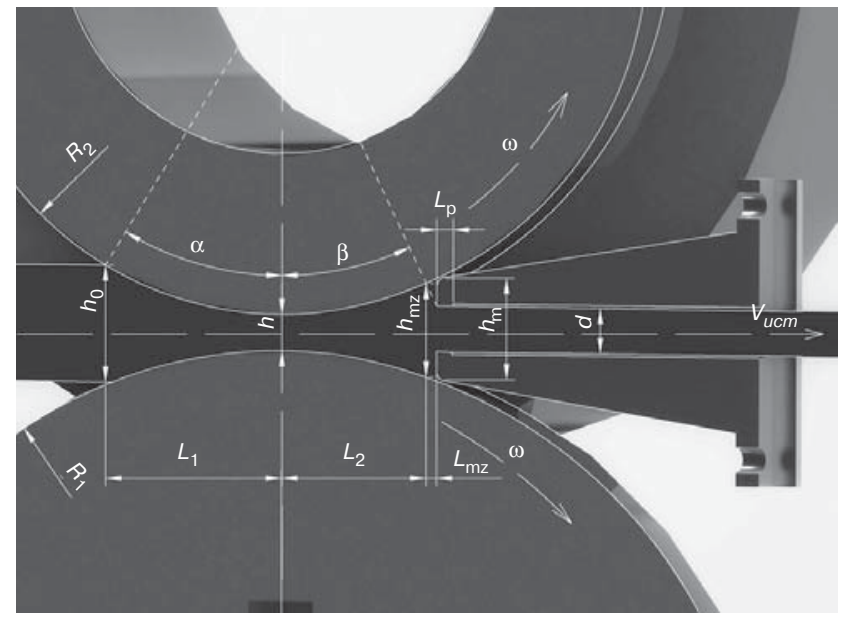

Fig. 2. Flowchart of combined rolling-extrusion process 
Table 4

Energy-power parameters of alloys processing on CRE-200 plant

\begin{tabular}{|c|c|c|c|c|c|c|c|}
\hline \multirow{2}{*}{\multicolumn{2}{|c|}{ Ag6 alloy }} & \multicolumn{3}{|c|}{$T_{s}=400^{\circ} \mathrm{C}$} & \multicolumn{3}{|c|}{$T_{s}=550^{\circ} \mathrm{C}$} \\
\hline & & 4.4 & 7.3 & 14.3 & 4.4 & 7.3 & 14.3 \\
\hline \multirow{2}{*}{$\xi=0.50 \mathrm{~s}^{-1}$} & $\mathrm{P}_{\text {roll, }} \mathrm{kN}$ & 215.47 & 238.37 & 251.38 & 61.05 & 68.68 & - \\
\hline & $P_{\text {die }}, k N$ & 143.25 & 187.85 & 239.85 & 40.59 & 54.13 & - \\
\hline \multirow{2}{*}{$\xi=1.50 \mathrm{~s}^{-1}$} & $\mathrm{P}_{\text {roll, }}, \mathrm{kN}$ & 298.07 & 331.29 & 359.12 & 68.23 & 72.72 & - \\
\hline & $P_{\text {die }}, k N$ & 198.16 & 261.08 & 342.64 & 45.36 & 57.31 & - \\
\hline \multirow{2}{*}{\multicolumn{2}{|c|}{01417 alloy }} & \multicolumn{3}{|c|}{$T_{s}=400^{\circ} \mathrm{C}$} & \multicolumn{3}{|c|}{$T_{s}=550^{\circ} \mathrm{C}$} \\
\hline & & 4.4 & 7.3 & 14.3 & 4.4 & 7.3 & 14.3 \\
\hline \multirow{2}{*}{$\xi=0.50 \mathrm{~s}^{-1}$} & $\mathrm{P}_{\text {roll, }} \mathrm{kN}$ & 93.37 & 101.00 & 112.23 & 53.87 & 56.56 & 58.36 \\
\hline & $P_{\text {die, }}, k N$ & 62.07 & 79.60 & 107.08 & 35.81 & 44.57 & 55.68 \\
\hline \multirow{2}{*}{$\xi=1.50 \mathrm{~s}^{-1}$} & $\mathrm{P}_{\text {roll, }}, \mathrm{kN}$ & 118.51 & 133.32 & 139.16 & 64.64 & 68.68 & 71.82 \\
\hline & $P_{\text {die, }}, k N$ & 78.79 & 105.07 & 132.77 & 42.97 & 54.13 & 68.53 \\
\hline \multirow{2}{*}{$\xi=10 \mathrm{~s}^{-1}$} & $\mathrm{P}_{\text {roll, }} \mathrm{kN}$ & 179.56 & 197.96 & 210.98 & 125.69 & 137.36 & 148.14 \\
\hline & $P_{\text {die, }}, k N$ & 119.37 & 156.01 & 201.30 & 83.56 & 108.25 & 141.34 \\
\hline \multirow{2}{*}{\multicolumn{2}{|c|}{8176 alloy }} & \multicolumn{3}{|c|}{$T_{S}=400^{\circ} \mathrm{C}$} & \multicolumn{3}{|c|}{$T_{s}=550^{\circ} \mathrm{C}$} \\
\hline & & 4.4 & 7.3 & 14.3 & 4.4 & 7.3 & 14.3 \\
\hline \multirow{2}{*}{$\xi=0.50 \mathrm{~s}^{-1}$} & $\mathrm{P}_{\text {roll, }} \mathrm{kN}$ & 68.23 & 72.72 & 76.31 & 28.73 & 30.30 & 31.42 \\
\hline & $P_{\text {die, }}, k N$ & 45.36 & 57.31 & 72.81 & 19.10 & 23.88 & 29.98 \\
\hline \multirow{2}{*}{$\xi=1.50 \mathrm{~s}^{-1}$} & $\mathrm{P}_{\text {roll, }}, \mathrm{kN}$ & 79.01 & 84.84 & 89.78 & 32.32 & 32.32 & 31.42 \\
\hline & $P_{\text {die, }}, k N$ & 52.52 & 66.86 & 85.66 & 21.49 & 25.47 & 29.98 \\
\hline \multirow{2}{*}{$\xi=10 \mathrm{~s}^{-1}$} & $\mathrm{P}_{\text {roll, }} \mathrm{kN}$ & 122.10 & 133.32 & 139.16 & 39.50 & 40.40 & 40.40 \\
\hline & $P_{\text {die }}, k N$ & 81.17 & 105.07 & 132.77 & 26.26 & 31.84 & 38.55 \\
\hline
\end{tabular}
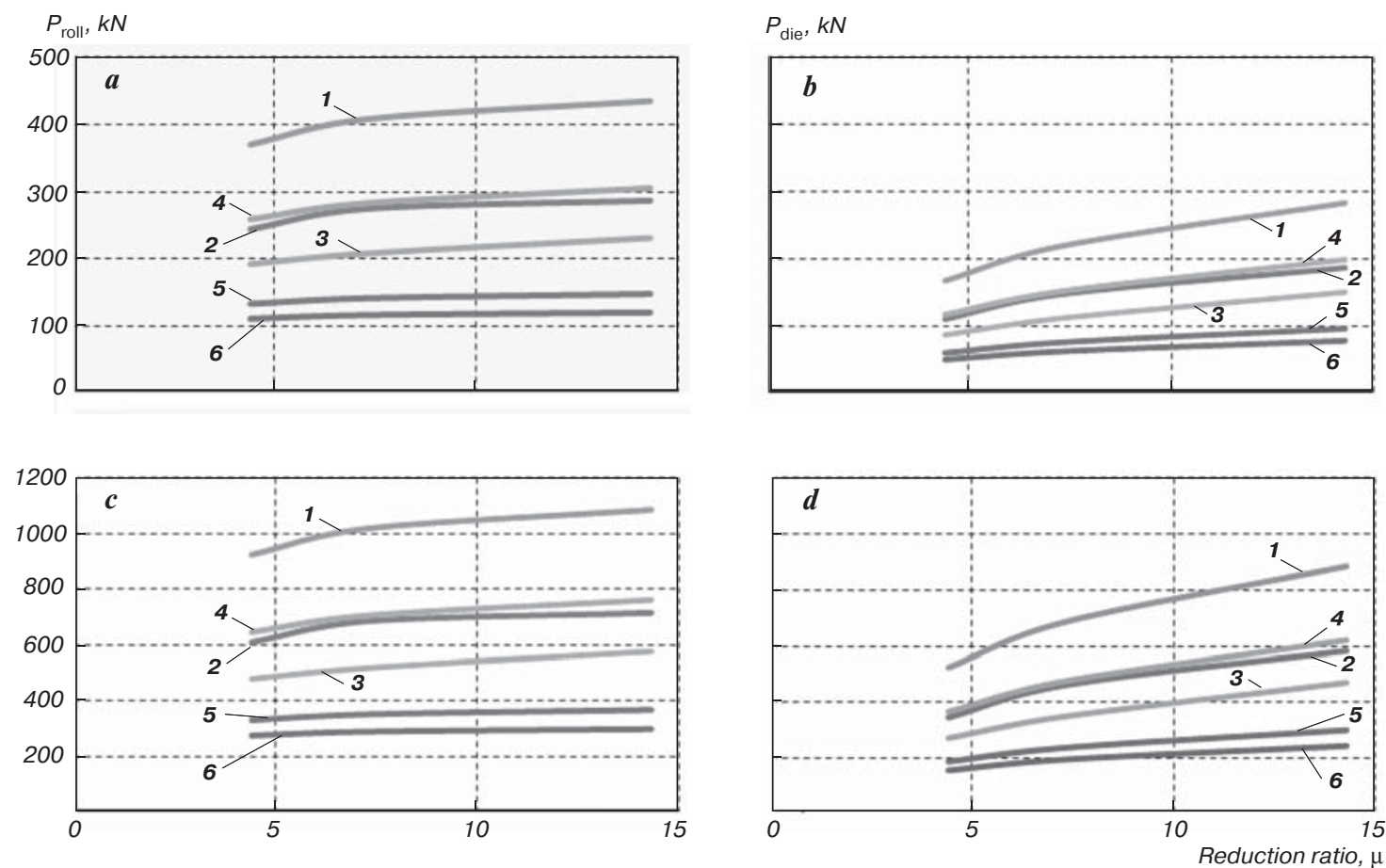

Fig. 3. Changes of energy-power parameters of combined rolling-extrusion processing of 01417 alloy on CCRE-2.5 $(a, b)$ and CCRE-4 (c, $d)$ plants: $1-T_{s}=400{ }^{\circ} \mathrm{C}, \xi=10,0 \mathrm{l} / \mathrm{s} ; 2-T_{s}=400{ }^{\circ} \mathrm{C}, \xi=1,50 \mathrm{l} / \mathrm{s} ; 3-T_{s}=400{ }^{\circ} \mathrm{C}, \xi=0,50 \mathrm{l} / \mathrm{s} ; 4-T_{s}=550{ }^{\circ} \mathrm{C}, \xi=10,01 / \mathrm{s} ; 5-T_{s}=550{ }^{\circ} \mathrm{C}$, $\xi=1,50 \mathrm{l} / \mathrm{s} ; 6-T_{s}=550^{\circ} \mathrm{C}, \xi=0,50 \mathrm{l} / \mathrm{s}$ 

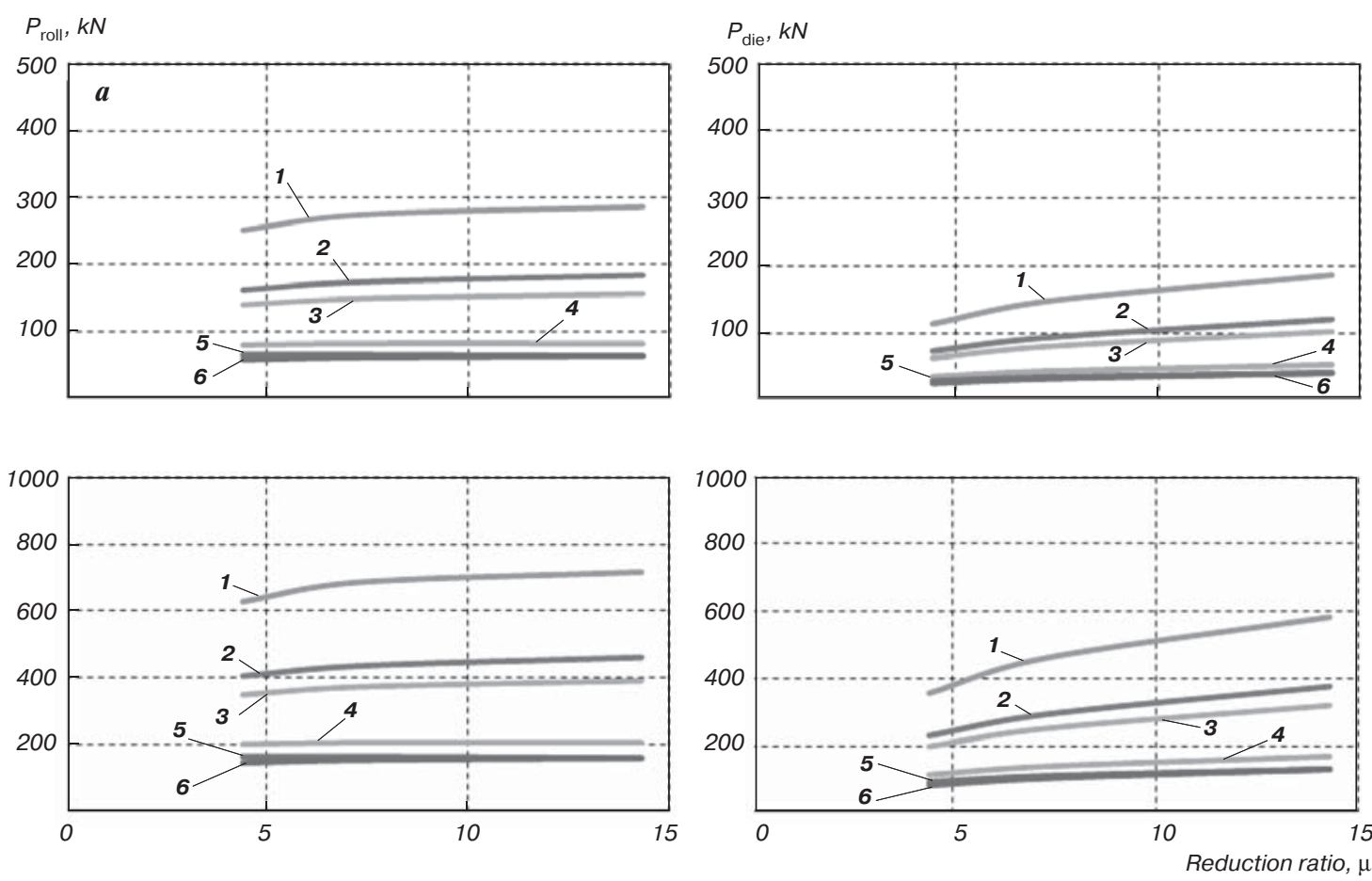

Fig. 4. Changes of energy-power parameters of combined rolling-extrusion processing of 8176 alloy on CCRE-2.5 $(a, b)$ and CCRE-4 ( $c, d)$ plants: $1-T_{s}=400{ }^{\circ} \mathrm{C}, \xi=10,0 \mathrm{l} / \mathrm{s} ; 2-T_{s}=400{ }^{\circ} \mathrm{C}, \xi=1,50 \mathrm{l} / \mathrm{s} ; 3-T_{s}=400{ }^{\circ} \mathrm{C}, \xi=0,50 \mathrm{l} / \mathrm{s} ; 4-T_{s}=550{ }^{\circ} \mathrm{C}, \xi=10,01 / \mathrm{s} ; 5-T_{s}=550{ }^{\circ} \mathrm{C}$, $\xi=1,50 \mathrm{l} / \mathrm{s} ; 6-T_{s}=550^{\circ} \mathrm{C}, \xi=0,50 \mathrm{l} / \mathrm{s}$

In Table 5 are listed the energy-power parameters of AMg6 alloy processing on CCRE-2.5 and CCRE-4 plants, which have maximum values. Obviously, the efforts on both rolls and die for this alloy grow as the CCRE-2.5 roll groove sizes are rising and achieve $740 \mathrm{kN}$ and $480 \mathrm{kN}$ respectively at strain rate $\xi=$ $=1.5 \mathrm{~s}^{-1}$, semifinished product temperature $T_{s}=400^{\circ} \mathrm{C}$ and stretching of 14.3. At a temperature of $400{ }^{\circ} \mathrm{C}$, calculated efforts on rolls and die for AMG6 alloy treatment on CCRE-4 plant are grown significantly (more than twice), which can lead to the tool breakage on realizing CRE process.
That's why it is recommended to carry out combined rolling-extrusion process for this alloy at light deformation degrees and temperatures of $500-550^{\circ} \mathrm{C}$. Calculations for AMg6 alloy at strain rate $\xi=10 \mathrm{~s}^{-1}$ has not been fulfilled, since contraction cracks on press-products are forming at such strain rate and given temperatures, which has been verified by experimental investigations [18].

Analysing obtained data, one can also conclude that the AMg6 alloy treatment at a temperature $T_{S}=550{ }^{\circ} \mathrm{C}$ and strain rate above $\xi=0.5 \mathrm{~s}^{-1}$ is discouraged in consequence of its low plasticity in the given temperature and speed range.

Table 5

\section{Energy-power parameters of an AMg6 alloy processing on CCRE-2.5 and CCRE-4 plants}

\begin{tabular}{|c|c|c|c|c|c|c|c|}
\hline \multirow{2}{*}{\multicolumn{2}{|c|}{ An AMg6 alloy }} & \multicolumn{3}{|c|}{$T_{S}=400^{\circ} \mathrm{C}$} & \multicolumn{3}{|c|}{$T_{S}=550^{\circ} \mathrm{C}$} \\
\hline & & 4.4 & 7.3 & 14.3 & 4.4 & 7.3 & 14.3 \\
\hline \multicolumn{8}{|c|}{ CCRE-2.5 plant } \\
\hline \multirow{2}{*}{$\xi=0.5 \mathrm{~s}^{-1}$} & $P_{\text {roll, }}, \mathrm{kN}$ & 444.09 & 491.27 & 518.10 & 125.82 & 141.55 & - \\
\hline & $P_{\text {die, }}, \mathrm{kN}$ & 201.33 & 264.48 & 337.93 & 57.04 & 76.21 & - \\
\hline \multirow{2}{*}{$\xi=1.5 \mathrm{~s}^{-1}$} & $P_{\text {roll, }}, \mathrm{kN}$ & 614.32 & 682.78 & 740.15 & 140.63 & 149.88 & - \\
\hline & $P_{\text {die, }}, \mathrm{kN}$ & 278.50 & 367.58 & 482.76 & 63.75 & 80.69 & - \\
\hline \multicolumn{8}{|c|}{ CCRE-4 plant } \\
\hline \multirow{2}{*}{$\xi=0.5 \mathrm{~s}^{-1}$} & $P_{\text {roll, }}, \mathrm{kN}$ & 1109,31 & 1227,17 & 1294,19 & 314.30 & 353.59 & - \\
\hline & $P_{\text {die, }}, \mathrm{kN}$ & 629.18 & 826.14 & 1054,39 & 178.27 & 238.04 & - \\
\hline \multirow{2}{*}{$\xi=1.5 \mathrm{~s}^{-1}$} & $P_{\text {roll, }}, \mathrm{kN}$ & 1534,54 & 1705,56 & 1848,84 & 351.28 & 374.39 & - \\
\hline & $P_{\text {die, }}, \mathrm{kN}$ & 870.37 & 1148,19 & 1506,27 & 199.24 & 252.04 & - \\
\hline
\end{tabular}




\section{Conclusion}

Thus, the fulfilled calculations has shown that lowplastic aluminium alloys have to be processed at high blank temperatures (up to $550{ }^{\circ} \mathrm{C}$ ) and relatively low deformation rates $\left(\xi=0.5-1.5 \mathrm{~s}^{-1}\right)$, which leads to decreasing the energy-power parameters of CRE process. The treatment temperature should be defined more accurately for each specific alloy, however it should lie in such a range which exclude temperature cracks formation on press-goods at given deformation rate. Energy-power parameters of combined treatment significantly grow as rolls diameter and respectively groove size are enlarging, so it is necessary to provide high durability of roller and press instrument.

The results of the investigations are recommended to be used in the combined processing technology of aluminium alloys treatment designing and mastering at Irkutsk aluminium smelter.

\section{References}

1. Belyy D. I. Aluminium alloys for leads of cable products. Kabeli i Provoda. 2012. No. 1. pp. 8-15.

2. GOST 7871-75. Aluminium and aluminium alloys tiller wire. Specifications. Introduced: 1976-07-01. Moscow : Izdatelstvo standartov, 1990 (reissue with changes).

3. Kornilov V. N. Aluminium alloys continuous extrusion with welding. Krasnoyarsk : Izdatelstvo pedagogicheskogo instituta, $1993.216 \mathrm{p}$.

4. Belov N. A., Alabin A. N., Teleuova A. R. Comparative analysis of alloying additives as applied to the production of heat-resistant aluminium-base wires. Metal Science and Heat Treatment. 2012. Vol. 53. Iss. 9-10. pp. 455-459.

5. Mogucheva A., Zyabkin D., Kaibyshev R. Effect of the thermomechanical processing on microstructure and properties of an $\mathrm{Al}-\mathrm{Ce}$ alloy. Materials Science Forum. 2012. Vol. 706709. pp. 361-366.

6. Liao H., Liu Y., Lü C., Wang Q. Mechanisms for Ceinduced remarkable improvement of conductivity in $\mathrm{Al}$ alloys. Journal of Materials Research. 2017. Vol. 32. Iss. 3. pp. 566-574.

7. Liao H., Wu Y., Wang Y. Microstructure evolution of Al $0.35 \% \mathrm{Si}-0.2 \% \mathrm{Mg}-0.3 \% \mathrm{Ce}$ alloy during hot extrusion and its contributions to performances. Journal of Materials Engineering and Performance. 2015. Vol. 24. pp. 2503-2510.

8. Zhao, Q., Qian, Z., Cui, X., Wu, Y., Liu, X. Optimizing microstructures of dilute $\mathrm{Al}-\mathrm{Fe}-\mathrm{Si}$ alloys designed with enhanced electrical conductivity and tensile strength. Journal of Alloys and Compounds. 2015. Vol. 650. pp. 768-776.

9. Shakiba M., Parson N., Chen X.-G. Hot deformation behavior and rate-controlling mechanism in dilute $\mathrm{Al}-\mathrm{Fe}-\mathrm{Si}$ alloys with minor additions of $\mathrm{Mn}$ and $\mathrm{Cu}$. Materials Science and Engineering: A. 2015. Vol. 636. pp. 572-581.

10. Shakiba M., Parson N., Chen X.-G. Effect of Iron and Silicon Content on the Hot Compressive Deformation Behavior of Dilute $\mathrm{Al}-\mathrm{Fe}-\mathrm{Si}$ Alloys. Journal of Materials Engineering and Performance. 2015. Vol. 24. Iss. 1. pp. 404-415.

11. Wang M., Xu W., Han Q. Effect of heat treatment on controlling the morphology of AlFeSi phase in A380 alloy. International Journal of Metal Casting. 2016. Vol. 10. Iss. 4. pp. 516-523.

12. Shi Z. M., Gao K., Shi Y. T., Wang Y. Microstructure and mechanical properties of rare-earth-modified $\mathrm{Al}-1 \mathrm{Fe}$ binary alloys. Materials Science and Engineering: A. 2017. Vol. 632. pp. 62-71.

13. Shi, J., Hou, L., Zuo, J., Zhuang, L., Zhang, J. Cryogenic rolling-enhanced mechanical properties and microstructural evolution of $5052 \mathrm{Al}-\mathrm{Mg}$ alloy. Materials Science and Engineering: A. 2017. Vol. 701. pp. 274-284.

14. Fereshteh-Saniee F., Fakhar N., Asgari M., Mahmudi R. A new experimental-numerical approach for studying the effects of gas pressure profile on superplastic forming characteristics of $\mathrm{Al}-\mathrm{Mg} 5.6$ alloy. The International Journal of Advanced Manufacturing Technology. 2017. Vol. 91. Iss. 5-8. pp. 17711780.

15. Puna S. C., Wangc W., Khalajhedayatib A., Schulerb J. D., Trelewiczc J. R., Rupert T. J. Nanocrystalline Al $\mathrm{Mg}$ with extreme strength due to grain boundary doping. Materials Science and Engineering: A. 2017. Vol. 696. pp. 400406.

16. Tang Y., Goto W., Hirosawa S., Horita Z., Lee S., Matsuda K., Terada D. Concurrent strengthening of ultrafinegrained age-hardenable $\mathrm{Al}$ - Mg alloy by means of high-pressure torsion and spinodal decomposition. Acta Materialia. 2017. Vol. 131. pp. 57-64.

17. Valdes-Tabernero M. A., Sancho-Cadenas R., Sabirov I., Murashkin M. Yu, Ovidko I. A., Galvez F. Effect of SPD processing on mechanical behavior and dynamic strain aging of an $\mathrm{Al}-\mathrm{Mg}$ alloy in various deformation modes and wide strain rate range. Materials Science and Engineering: A. 2017. Vol. 696. pp. 348-359.

18. Sidelnikov S. B., Dovzhenko N. N., Zagirov N. N. Joint and combined methods of processing of non-ferrous metals and alloys : monography. Moscow : MAKS Press. 2005. $344 \mathrm{p}$.

19. Grischenko N. A., Sidelnikov S. B., Gubanov I. Y. et al. Mechanical properties of aluminium alloys. Krasnoyarsk : Sibirskiy Federalnyy Universitet, 2012. 196 p.

20. Sidelnikov S. B., Konstantinov I. L., Voroshilov D. S. The rolling technology : textbook. Krasnoyarsk : Sibirskiy Federalnyy Universitet, 2016. $180 \mathrm{p}$.

21. Sidelnikov S. B., Dovzhenko N. N., Drozdova T. N. et al. Experimental research of combined rolling-extrusion processing for the wire rod production of $\mathrm{Al}-\mathrm{Fe}$ system alloys. Proizvodstvo Prokata. 2015. No. 9. pp. 40-46.

22. Voroshilov D. S., Sidelnikov S. B., Rudnitskiy E. A. Development of the wire manufacturing of $\mathrm{Al}$ - REM system high-alloy alloys with the use of the combined treatment method. Zhurnal Sibirskogo Federalnogo Universiteta. Tekhnika i Tekhnologii. 2015. Vol. 8. No. 1. pp. 61-65. 